\title{
Shaping Public Health Initiatives in Kidney Diseases: The Peer Kidney Care Initiative
}

\author{
James B. Wetmore ${ }^{a, b}$ David T. Gilbertson ${ }^{a}$ Allan J. Collins ${ }^{a, c}$ \\ ${ }^{a}$ Chronic Disease Research Group, Minneapolis Medical Research Foundation, ${ }^{b}$ Department of Medicine, \\ Division of Nephrology, Hennepin County Medical Center, and ' Department of Medicine, University of Minnesota, \\ Minneapolis, MN, USA
}

\section{Key Words}

Dialysis · End-stage renal disease $\cdot$ Healthy people .

Public health

\begin{abstract}
Background: While broad-based societal efforts to improve public health have targeted disorders such as cardiovascular disease and cancer for several decades, efforts devoted to kidney disease have developed only more recently. The Peer Kidney Care Initiative, a novel effort designed to address knowledge gaps in the care of patients with kidney disease, examines key disease processes, the roles of geography and seasonality on outcomes, and longitudinal trends in outcomes over time. Summary: Admissions for gastrointestinal bleeds increased approximately 28\% between 2004 and 2011 in prevalent patients. Infection with Clostridium difficile increased nearly 70\% between 2003 and 2010 in patients within a year of initiation. Admissions for heart failure in prevalent patients decreased approximately 25\% between 2004 and 2012, but admissions for volume overload increased a nearly equal amount. Incidence rates varied substantially by geographic region, such that unadjusted rates in the highest region were nearly double than those in the lowest. There was seasonal variation in all-cause mortality of approximately $15-20 \%$ in both incident and prevalent patients, suggesting a link between cardiovascular events and
\end{abstract}

\section{KARGER}

E-Mail karger@karger.com

www.karger.com/bpu seasonally related environmental conditions. New cases of end-stage renal disease fell from 385 per million population in 2003 to 344 in 2012, a decline of approximately 10\%. Key Messages: Peer complements existing kidney disease epidemiologic efforts by examining specific actionable disease entities, exploring geographic variation in care, highlighting the role of seasonality on outcomes, and emphasizing the importance of trending outcomes over time as overall societal progress is being made.

(c) 2016 S. Karger AG, Basel

\section{Introduction}

The concept that societies should engage in broadbased campaigns to improve public health is now several decades old. In the United States, the 1979 Surgeon General's first Healthy People report [1] marked a paradigm shift by which the establishment of society-wide healthpromotion goals, coupled with a framework to monitor progress toward attaining them, became paramount. This decennial effort continues to the present day [2] and is not confined to the United States [3].

In the United States and other developed countries, the emphasis of the Healthy People initiatives and of entities such as the World Health Organization (WHO) have, understandably, focused on non-communicable
(C) 2016 S. Karger AG, Basel

0253-5068/16/0413-0151\$39.50/0
James B. Wetmore, MD, MS

Chronic Disease Research Group

Minneapolis Medical Research Foundation

914 South 8th Street, Suite S4.100, Minneapolis, MN 55404 (USA)

E-Mail James.Wetmore@hcmed.org 
diseases (NCDs), principally cardiovascular disease (CVD) and cancer. Traditionally, kidney disease has not been the focus substantial attention. However, kidney disease is now an area targeted for scrutiny. For example, WHO states, in item 19 of the UN Political Declaration on NCDs [4], that '...renal, oral and eye diseases pose a major health burden for many countries and that these diseases share common risk factors and can benefit from common responses to non-communicable diseases,' while the Healthy People 2020 project explicitly lists a series of chronic kidney disease (CKD) public health targets [5]. Given the growing size of the maintenance dialysis population, a phenomenon driven by substantial increases in longevity [6], it may now be an appropriate time to consider how best to evaluate the landscape of kidney disease, to select areas for particular scrutiny, and to monitor progress over time. Supplementing established public health efforts, such as the United States Renal Data System [7] and the Dialysis Outcomes and Practice Patterns Study [8], the Peer Kidney Care Initiative was formed to provide a unique perspective on these endeavors. Peer, established by the Chief Medical Officers of 13 US dialysis provider organizations, was formally constituted in 2014 to render novel insights and fill important knowledge gaps, with the intention that provider organizations could learn from one another and advance patient care. Through the analytic expertise of the Chronic Disease Research Group, certain areas of particular clinical importance were targeted in an attempt to help shape the public health agenda in CKD and end-stage renal disease (ESRD).

\section{The Peer Kidney Care Initiative: Foci of Study in a Changing Health Landscape}

While several health initiatives have been instrumental in shaping the public health agenda in the care of patients with kidney diseases $[7,8]$, the organic interactions that arose from the creation of the Peer collaborative group generated a consensus that important gaps remained. As a result, several focus areas were established. First, certain actionable diseases, some of which have been traditionally understudied, were specifically selected for scrutiny. Second, geographic variation in outcomes, which has not been comprehensively explored, would be addressed more completely to determine how geographic location might impact the assessment of care across the United States. Third, the potential association of seasonality with important outcomes would be investigated. Finally, trends in progress over time would be examined in the context of a justifying framework. Salient findings from Peer in each of these areas are discussed below.

\section{Novel Disease Findings}

While many disease processes were explored in the Peer report, several are particularly worthy of mention. Close examination of gastrointestinal (GI) bleeds, intestinal infection with Clostridium difficile ('C. diff'), congestive heart failure (CHF) and volume overload, and chronic lung disease provided new insights.

GI bleeds appear to be an increasingly important reason for hospital admissions in maintenance dialysis patients $[6,9,10]$. Based on billing claims data, admissions attributed to GI bleeds have gradually increased since at least 2004, and began a more pronounced rise after 2010 . Indeed, the rate among prevalent patients increased by approximately 28\% between 2004 and 2011, from approximately 1.8 to 2.3 admissions per 100 patient-years. Notably, 2011 corresponds to the introduction of the revised Prospective Payment System (PPS). How admissions for GI bleeds and the PPS introduction might be linked is uncertain, but it is possible that the lower mean hemoglobin levels in evidence since the introduction of the PPS [11-15] may have 'unmasked' subclinical GI bleeds, the main indication of which may be a drop in, or lower-than-expected level of, hemoglobin. Another possibility is that lower hemoglobin levels prompt a clinical workup for a presumed GI bleed, many of which are 'empirically' diagnosed even in the absence of a positive upper or lower endoscopy. Whether GI bleeds are truly increasing or whether this is a phenomenon associated with lower mean achieved hemoglobin levels is uncertain, but a subject that needs to be further studied.

Infection with $C$. diff, a major focus for hospitalized patients in the general population [16-18], was examined in the Peer report [6]. Admissions for C. diff infections among new dialysis patients (within the first 12 months after initiation) increased nearly $69 \%$, from approximately 1.4 to 2.5 admissions per 100 patient-years between 2003 and 2010. This is important because C. diff infection can contribute to malnourishment at a time - dialysis initiation - when patients are particularly vulnerable to catastrophic illness and death. Likewise, $C$. diff admissions in prevalent patients have also increased. The admission pattern shows evidence of seasonality, perhaps as a 'trailing phenomenon' relative to other infections requiring treatment with broad-spectrum antibiotics. Given the in- 
creased scrutiny of readmissions, $C$. diff should be considered a target for quality improvement efforts, given a high recurrence and readmission rate $[19,20]$.

$\mathrm{CHF}$ is one of the most common reasons for admission in both the general [21] and the dialysis populations [6] and, because of high readmission rates, is a target of the Centers for Medicare and Medicaid Services (CMS) quality-improvement efforts [22]. Consideration of CHF in maintenance dialysis patients is, however, a wholly different phenomenon relative to the general population. Many admissions for ' $\mathrm{CHF}$ ' in dialysis patients might more properly be termed 'circulatory overload,' reflecting inadequate ultrafiltration rather than true compromised left ventricular systolic function. Inability to achieve a patient's dry weight resulting in an admission requiring urgent ultrafiltration might therefore more properly be coded as 'fluid overload,' a diagnosis with its own ICD-9 (Internal Classification of Diseases, Ninth Revision, Clinical Modification) code (276). Close inspection of the data demonstrates difficulties in drawing informed conclusions. Peer reported that admissions for heart failure decreased approximately $25 \%$ in prevalent patients between 2004 and 2012, from roughly 16 admissions per 100 patient-years to 12 - an apparently welcome development. However, admissions for fluid overload increased during this time period by about 2.5 -fold, from roughly 2.0 to 5.5 admissions per 100 patient-years, suggesting that there is no evidence that the nephrology community has become markedly better over time at managing volume issues in dialysis patients. Whether this change in coding pattern represents a genuine effort to apply greater specificity or reflects attempts by facilities to avoid penalties for 30-day readmissions is uncertain.

Lastly, chronic obstructive pulmonary disease (COPD) was also examined in detail in Peer [6]. While rates of admission for both incident and prevalent patients have been fairly stable since approximately 2008, Peer described substantial ( $>2$-fold) unadjusted geographic variation across regions, the reasons for which should be investigated in this understudied area. Not unexpectedly, this disorder also showed substantial seasonality, whether coded as the primary or leading secondary diagnosis, with admissions rising sharply during the coldest months.

\section{Geographic Variation}

Geographic variation is given substantial emphasis in the Peer report. The overall stabilization of incident rates in the United States [7] belies the finding that incidence rates vary by US census region, with the east south cen- tral, west south central, and south Atlantic regions demonstrating the highest absolute incident rates of ESRD (fig. 1) [6]. The highest regional absolute incident rates are nearly double the lowest regional rates, and while the data presented are unadjusted, it is unlikely that case-mix could account for all of the variation present. Differences do not end after patients initiate dialysis, as substantial geographic variation is present for several key diagnoses such as cardiovascular disorders, infectious disorders, GI bleeds, and COPD.

One striking finding is variation in the percentages of patients who are under a nephrologist's care before starting dialysis. As of 2011 , nearly $80 \%$ of patients in New England had seen a nephrologist before initiating dialysis, compared with $62 \%$ in the west south central region [6]. Even if case-mix adjustment were to attenuate some of these differences, increased emphasis should be placed on facilitating nephrologist care before dialysis initiation in all regions, and especially in regions that appear to be underperforming.

\section{Seasonality}

Seasonality is given considerable treatment in the Peer report. Individually, some patterns are as one would suspect (fig. 2). For example, certain infectious causes of hospitalization, such as pneumonia and influenza, primarily peak in colder months, generally consistent with the general population [23]; relatedly, exacerbations of COPD also occur in the winter, as in the general population [24]. However, other conditions, which might appear to have more tenuous associations with season, also manifest more dramatically in winter months, such as overall CVD, acute coronary syndrome, and heart failure/cardiomyopathy. Collectively, there is a clear seasonal variation in all-cause mortality of approximately $15-20 \%$ in both incident and prevalent patients. This suggests a link between cardiovascular events (and perhaps other ostensibly non-infectious events) and seasonally related environmental conditions in dialysis patients. One hypothesis to explain this might be that subclinical infections, and the systemic inflammation they promote, might provoke cardiovascular events in ill-defined ways, but this requires much future study.

Regarding policy prescriptions, what might this mean? First, increased efforts at cleaning surfaces and touch points within the dialysis unit during the winter months might be warranted. Second, clinicians might be well served to alter their index of suspicion for certain events, 
Fig. 1. ESRD incidence rates by geographic region.

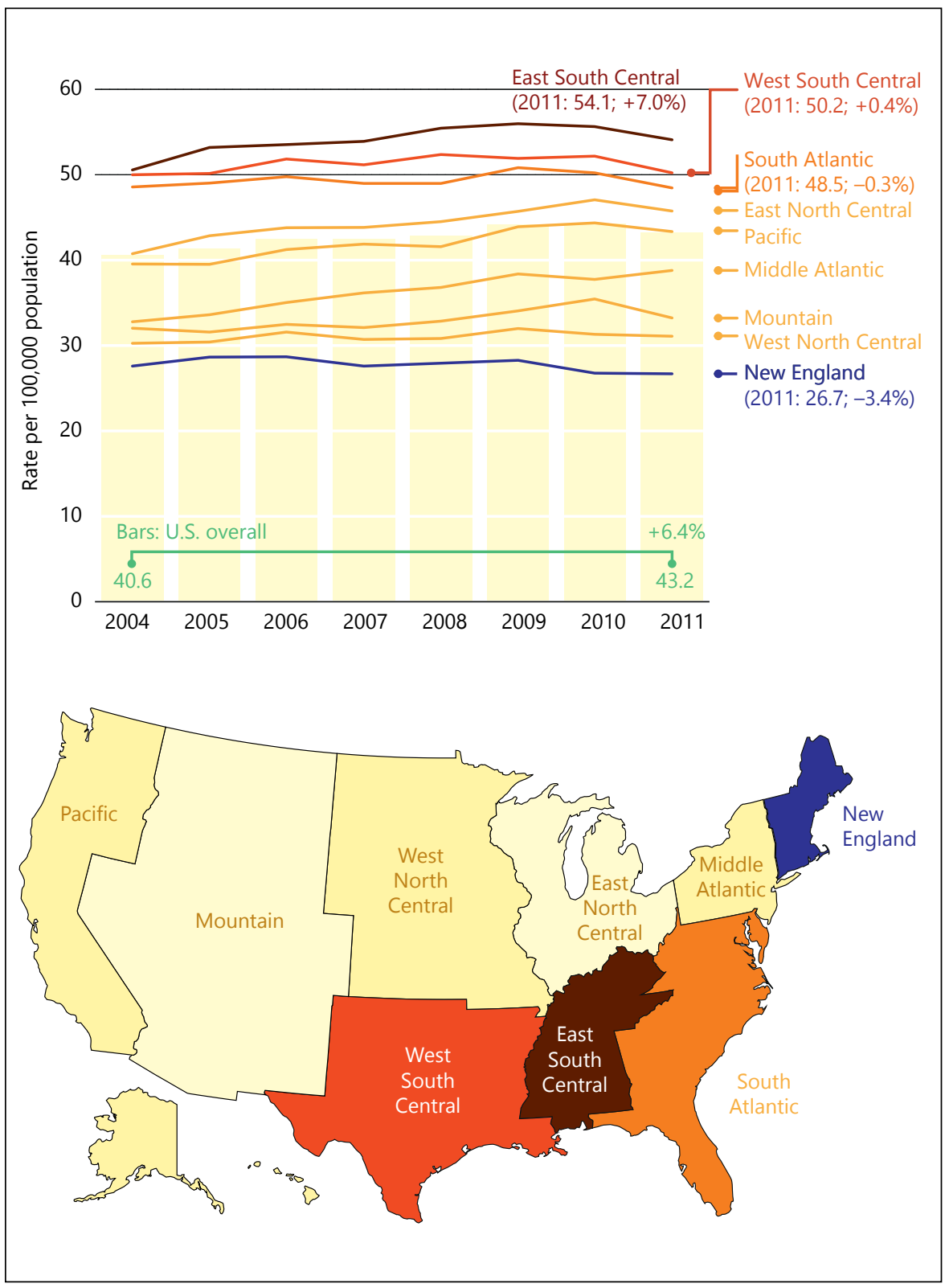

including cardiovascular events, during less temperate months. Lastly, potential links between seasonality and CVD outcomes should become a research priority.

\section{Monitoring Progress: Elements of an Effective Framework}

Substantial progress has recently been made in the care of dialysis patients. For example, the incidence rate, adjusted for age, sex, race, and cause of ESRD, has declined since at least 2003, and perhaps even earlier. The Healthy People 2020 goal CKD-8 [5], which calls for 'reduc(ing) the number of new cases of ESRD per million population' has been met, with new cases falling from 385 per million population in 2003 to 344 in 2012, a decline of approximately $10 \%$. Even more striking, in certain disadvantaged or at-risk groups, the decline in incidence rate is greater than the average decline, a finding that is the opposite of what might be expected. For example, for African Americans, the declinehasbeen 15\%; for Native Americans, $24 \%$; for Hispanics, $17 \%$; and for women, $12 \%$ [6]. 
Fig. 2. Seasonal pattern in admission rates for key disorders.

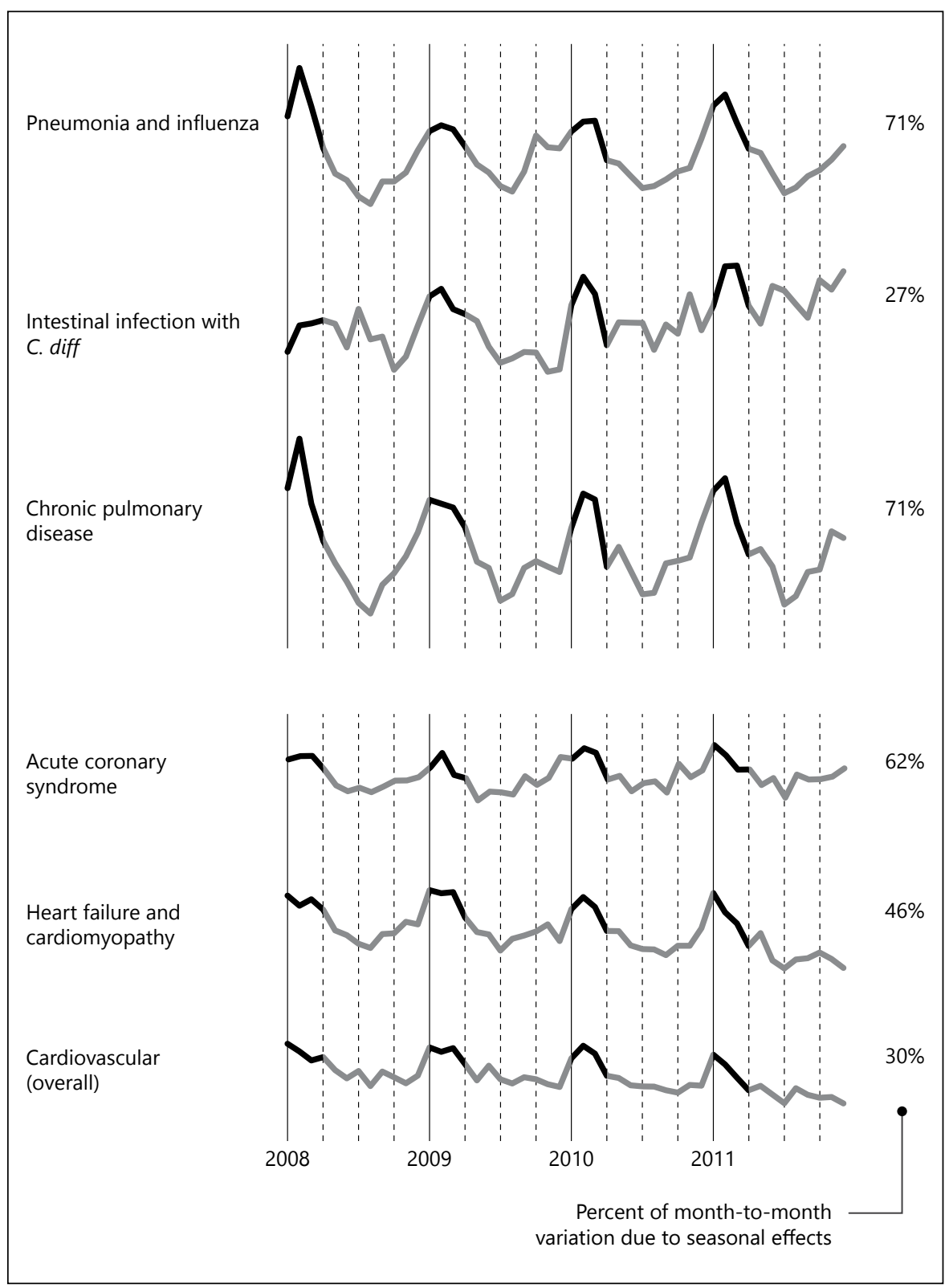

Likewise, improvements have occurred in the outcomes of prevalent dialysis patients. The annualized mortality rate has declined by about 30\% relative to 1999 . The death rate, which was 237 per 1,000 patient-years, exceeded the target of 190 set only 5 years ago (HP goal CKD-14.1) [5], and stood at 181 as of 2012 [6]. Likewise, other targets have been exceeded: the target for reduction in death during the first 3 months after dialysis initiation was 328.7 per 1,000 patient-years (Healthy People goal CKD-14.2) [5], and the death rate fell from 387 per 1,000 patient-years in 2003 to 312 in 2012; the cardiovascular death rate (Healthy People goal CKD-14.3, 80.9 per 1,000 patient-years) [5] fell from 116 per 1,000 patient-years to 76 over the corresponding interval [7]. Over this time, the mean lifespan of dialysis patients has increased by approximately $20 \%$.

Given these relatively dramatic improvements across the dialysis landscape, how might progress best be measured? One metric that ostensibly measures the quality of care is the standardized morality ratio (SMR), which variously relies on direct or indirect standardization to adjust for case-mix differences [25]. An SMR-based approach is 
useful to determine whether and how outcomes vary by geographic region and whether large variations in care exist [26]. These comparisons serve to highlight potential disparities present in a country and to permit scrutiny to be directed toward dialysis facilities that appear to be underperforming. Contrasts between units with high and low SMRs present an opportunity to discern whether differences in practice patterns between units can be leveraged to improve care for all.

However, overall societal progress cannot be adequately measured by SMRs, given that they are by nature cross-sectional and by definition centered at an intuitive value (e.g. 1.0 or 100) [27]. SMRs are not completely informative when care is likely to be improving across a population as a whole, as has been the case for maintenance dialysis care in the United States. An alternative approach used by WHO [28], measures progress over time within a geographic region, and each region serves as its own control over time. Peer relies heavily on this approach, because use of trends over time can complement insights derived from use of SMRs and can ameliorate some of the weaknesses of the latter. For example, when monitoring trends over time, facilities might be less likely to be 'penalized,' as can occur when SMRs are compared (because some units will invariably have lowerthan-average SMRs). Additionally, use of time trends does not invoke adjustments, which are essential when calculating SMRs and which are often incomplete or unsatisfying. While straightforward adjustment for factors such as age, sex, race, and cause of ESRD is common, these provide little insight to guide opportunities for improvement, since these factors are unmodifiable.

Similarly, geographically related factors that are likely to affect care but are not explicitly accounted for in adjustment, including socioeconomic factors, environmental factors such as pollution, local factors such as barriers to care, and idiosyncrasies of care delivery systems, are poorly captured in SMRs; in contrast, these are inherently accounted for, at least over the short term, when a facility is compared with itself over time (since these factors are unlikely to change rapidly within a geographic unit). The Peer report therefore emphasizes longitudinal comparisons wherever possible.

\section{Rating Dialysis Units: Insights from Peer}

Since 2014, CMS has pursued a policy of calculating, rating, and releasing to the public scores (in ascending order of 1-5 'stars') that putatively represent the quality of care provided by each facility. The individual facility's score is based on three standardized outcome measures (SMR, standardized hospitalization ratio, and standardized transfusion ratio), 2 process outcome measures (dialysis adequacy and hypercalcemia), and 2 vascular access measures (venous catheter use for longer than 90 days and arteriovenous fistula use), each of which is accorded a specific weight. The Peer analysis explored the theoretical effects of how facility ratings would change if different weights were reassigned to each measure [6]. There were several compelling reasons to engage in this exercise. First, because the relative weights assigned to each of the 7 measures are arbitrary, understanding how robust the rating system is compared with alternative weighting systems is important. Second, because each of the three standardized outcome measures is modelled, they are by definition associated with random error; because errors widen substantially when sample size is small, a much larger range of values becomes plausible. Third, these standardized outcome measures are themselves adjusted, and rely in part on information about comorbid conditions garnered from the Medical Evidence Report (form CMS-2728), which has been acknowledged by its creators to be imperfect [29]. Fourth, an arbitrary rescaling exercise occurs at the final step, whereby the top and bottom $10 \%$ of facilities are assigned 1 and 5 stars, respectively, while the middle $40 \%$ are assigned 3 stars. While this is not necessarily unreasonable, there is no objective basis for these cutpoints.

The Peer analysis demonstrated that increasing the weights of the standardized mortality and hospitalization ratios to $50 \%$ (from $22 \%$ ) resulted in substantial reclassification of units, with scores increasing for $29 \%$ of 1 -star facilities and decreasing for $34 \%$ of 5 -star facilities. Numerous other examples are presented, which generally serve to show that the 5-star rating system is sensitive to arbitrary weighting decisions. Given these demonstrated difficulties, caution should clearly be exercised when inferring quality from this system. Consolidating quality measures into a single score has an intuitive appeal, but substantial nuance is lost in so doing; as such, the nephrology community should be sober about the limitations of such a system.

\section{Conclusions}

Peer is a novel endeavor designed to improve the care of patients with kidney disease. Peer complements existing efforts by examining specific actionable disease enti- 
ties, explores geographic variation in care, highlights the role of seasonality in outcomes, and emphasizes the importance of trending outcomes over time to judge societal progress in improving patient care.

\section{Disclosure Statement}

Financial support for the Peer Kidney Care Initiative is provided by 13 participating dialysis provider organizations: American Renal Associates, Atlantic Dialysis Management Services, Centers for Dialysis Care, DaVita HealthCare Partners, Dialysis Clinic, Inc., DSI Renal, Fresenius Medical Care, Independent Dialysis Foundation, Northwest Kidney Centers, Renal Ventures Management, Satellite Healthcare, The Rogosin Institute, and US Renal
Care. The contract provides for the Minneapolis Medical Research Foundation authors to have final determination of manuscript content. Dr. J.B. Wetmore has served on advisory boards for Alexion. Dr. D.T. Gilbertson has provided consultation to GlaxoSmithKline and DaVita Clinical Research. Dr. A.J. Collins has provided consultation to Amgen, Relypsa, DaVita, NxStage, Keryx, and ZS Pharma.

\section{Acknowledgments}

The authors thank Chronic Disease Research Group colleagues Delaney Berrini, BS, for manuscript preparation, Susan Everson, $\mathrm{PhD}$, for assistance with data arrangement and graphical presentation, and Nan Booth, MSW, MPH, ELS, for manuscript editing.

\section{References}

1 National Institutes of Health: The Reports of the Surgeon General, Public Health and Disease Prevention. 2015. http://profiles.nlm. nih.gov/ps/retrieve/Narrative/NN/p-nid/63 (accessed September 3, 2015).

2 US Department of Health and Human Services: Healthy People 2020. http://www.healthy people.gov/2020/leading-health-indicators/ Leading-Health-Indicators-Developmentand-Framework (accessed September 3, 2015).

3 World Health Organization: About Health 2020. http://www.euro.who.int/en/healthtopics/health-policy/health-2020-theeuropean-policy-for-health-and-well-being/ about-health-2020 (accessed September 3, 2015).

4 United Nations: Resolution Adopted by the General Assembly: Annex, 66th Session, Agenda Item 117. http://www.who.int/nmh/ events/un_ncd_summit2011/political_declaration_en.pdf (accessed September 3, 2015).

5 US Department of Health and Human Services: Healthy People 2020: Chronic Kidney Disease.http://www.healthypeople.gov/2020/ topics-objectives/topic/chronic-kidney-disease (accessed September 3, 2015).

6 Weinhandl E, Constantini E, Everson S, Gilbertson D, Li S, Solid C, Anger M, Bhat JG, DeOreo P, Krishnan M, Nissenson A, Johnson D, Ikizler TA, Maddux F, Sadler J, Tyshler L, Parker T 3rd, Schiller B, Smith B, Lindenfeld S, Collins AJ: Peer kidney care initiative 2014 report: dialysis care and outcomes in the United States. Am J Kidney Dis 2015;65(6 suppl 1):Svi, S1-S140.

7 Saran R, Li Y, Robinson B, Ayanian J, Balkrishnan R, Bragg-Gresham J, Chen JT, Cope E, Gipson D, He K, Herman W, Heung M, Hirth RA, Jacobsen SS, Kalantar-Zadeh K, Kovesdy CP, Leichtman AB, Lu Y, Molnar MZ, Morgenstern H, Nallamothu B, O'Hare AM, Pisoni R, Plattner B, Port FK, Rao P, Rhee CM, Schaubel DE, Selewski DT, Shahin- ian V, Sim JJ, Song P, Streja E, Kurella Tamura M, Tentori F, Eggers PW, Agodoa LY, Abbott KC: US Renal Data System 2014 annual data report: epidemiology of kidney disease in the United States. Am J Kidney Dis 2015;66(1 suppl 1):Svii, S1-S305.

8 Arbor Research Collaborative for Health: Annual Report of the Dialysis Outcomes and Practice Patterns Study: Hemodialysis Data 1997-2011. http://www.dopps.org/annual report/ (accessed September 3, 2015).

9 Yang JY, Lee TC, Montez-Rath ME, Paik J, Chertow GM, Desai M, Winkelmayer WC: Trends in acute nonvariceal upper gastrointestinal bleeding in dialysis patients. J Am Soc Nephrol 2012;23:495-506.

10 Yang JY, Lee TC, Montez-Rath ME, Chertow GM, Winkelmayer WC: Risk factors of shortterm mortality after acute nonvariceal upper gastrointestinal bleeding in patients on dialysis: a population-based study. BMC Nephrol 2013;14:97.

11 Brunelli SM, Monda KL, Burkart JM, Gitlin M, Neumann PJ, Park GS, Symonian-Silver M, Yue S, Bradbury BD, Rubin RJ: Early trends from the study to evaluate the prospective payment system impact on small dialysis organizations (STEPPS). Am J Kidney Dis 2013;61:947-956.

12 Hirth RA, Turenne MN, Wilk AS, Wheeler JR, Sleeman KK, Zhang W, Paul MA, Nahra TA, Messana JM: Blood transfusion practices in dialysis patients in a dynamic regulatory environment. Am J Kidney Dis 2014;64:616-621.

13 Collins AJ, Foley RN, Herzog C, Chavers B, Gilbertson D, Herzog C, Ishani A, Johansen K, Kasiske B, Kutner N, Liu J, St Peter W, Ding S, Guo H, Kats A, Lamb K, Li S, Li S, Roberts T, Skeans M, Snyder J, Solid C, Thompson B, Weinhandl E, Xiong H, Yusuf A, Zaun D, Arko C, Chen SC, Daniels F, Ebben J, Frazier E, Hanzlik C, Johnson R, Sheets D, Wang X, Forrest B, Constantini E, Everson S, Eggers P,
Agodoa L: US Renal Data System 2012 annual data report. Am J Kidney Dis 2013;61(1 suppl 1):A1, e1-e476.

14 Centers for Medicare \& Medicaid Services: ESRD Prospective Payment System (ESRD PPS): Overview of 2011 and 2012 ClaimsBased Monitoring Program. http://www.cms. gov/Medicare/Medicare-Fee-for-ServicePayment/ESRDpayment/Spotlight.html (accessed September 3, 2015).

15 Gilbertson DT, Collins AJ, Foley R: Transition in Service Utilization: Vascular Access, Injectables, Hemoglobin Levels, and Transfusions. http://www.usrds.org/2012/pres/ASN2H/ Gilbertson_USRDS_2-hour_Full.pdf (accessed September 3, 2015).

16 Magill SS, Dumyati G, Ray SM, Fridkin SK: Evaluating epidemiology and improving surveillance of infections associated with health care, United States. Emerg Infect Dis 2015;21: 1537-1542.

17 Snydman DR, McDermott LA, Jacobus NV, Thorpe C, Stone S, Jenkins SG, Goldstein EJC, Patel R, Forbes BA, Mirrett S, Johnson S, Gerding DN: A US based National Sentinel Surveillance Study for the epidemiology of clostridium difficile associated diarrheal isolates and their susceptibility to fidaxomicin. Antimicrob Agents Chemother 2015;59:11.

18 Vindigni SM, Surawicz CM: C. difficile infection: changing epidemiology and management paradigms. Clin Transl Gastroenterol 2015;6:e99.

19 Olsen MA, Yan Y, Reske KA, Zilberberg M, Dubberke ER: Impact of clostridium difficile recurrence on hospital readmissions. Am J Infect Control 2015;43:318-322.

20 Chopra T, Neelakanta A, Dombecki C, Awali RA, Sharma S, Kaye KS, Patel P: Burden of clostridium difficile infection on hospital readmissions and its potential impact under the hospital readmission reduction program. Am J Infect Control 2015;43:314-317. 
21 Jencks SF, Williams MV, Coleman EA: Rehospitalizations among patients in the Medicare fee-for-service program. N Engl J Med 2009;360:1418-1428.

22 Centers for Medicare \& Medicaid Services: Readmissions Reduction Program. http:// www.cms.gov/Medicare/Medicare-Fee-forService-Payment/AcuteInpatientPPS/Readmissions-Reduction-Program.html (accessed September 3, 2015).

23 Murdoch KM, Mitra B, Lambert S, Erbas B: What is the seasonal distribution of community acquired pneumonia over time? A systematic review. Australas Emerg Nurs J 2014; 17:30-42.
24 Almagro P, Hernandez C, Martinez-Cambor P, Tresserras R, Escarrabill J: Seasonality, ambient temperatures and hospitalizations for acute exacerbation of COPD: a populationbased study in a metropolitan area. Int J Chron Obstruct Pulmon Dis 2015;10:899908.

25 Van den Broeck J, Brestoff J, Kaulfuss C: Epidemiology: principles and practical guidelines; in Van den Broeck J, Brestoff J (eds): Statistical Estimation. Netherlands, Springer, 2013, pp 417-438.
26 Liu J, Li S, Gilbertson DT, Monda KL, Bradbury BD, Collins AJ: Development of a standardized transfusion ratio as a metric for evaluating dialysis facility anemia management practices. Am J Kidney Dis 2014;64:608-615.

27 van Gestel YR, Lemmens VE, Lingsma HF, de Hingh IH, Rutten HJ, Coebergh JW: The hospital standardized mortality ratio fallacy: a narrative review. Med Care 2012;50:662-667.

28 World Health Organization: Noncommunicable Diseases: Country Profiles 2014. http:// www. who.int/global-coordinationmechanism/publications/ncds-country-profiles-eng.pdf?ua $=1$ (accessed September 3, 2015).

29 Eggers PW: CMS 2728: what good is it? Clin J Am Soc Nephrol 2010;5:1908-1909. 